Rodolfo Montironi • Roberta Mazzucchelli •

Theodorus van der Kwast

\title{
Morphological assessment of radical prostatectomy specimens. A protocol with clinical relevance
}

Published online: 27 May 2003

(C) Springer-Verlag 2003

\section{Virchows Arch (2003) 442:211-217}

The formula in the published article (page 212) was:

(Width $\times$ Height $\times$ Length $) \times 0.532$

The correct formula is:

$($ Width $\times$ Height $\times$ Length $) \times 0.523$

The online version of the original article can be found at http:// dx.doi.org/10.1007/s00428-002-0741-7

R. Montironi $(\bullet) \cdot$ R. Mazzucchelli

Institute of Pathological Anatomy,

University of Ancona School of Medicine,

Umberto $1^{\circ}$ Hospital60020 Torrette, Ancona, Italy

e-mail: r.montironi@unian.it

Tel.: +39-071-5964830

Fax: +39-071-889985

T. van der Kwast

Department of Pathology, Josephine Nefkens Institute,

Erasmus MC, Rotterdam, The Netherlands 